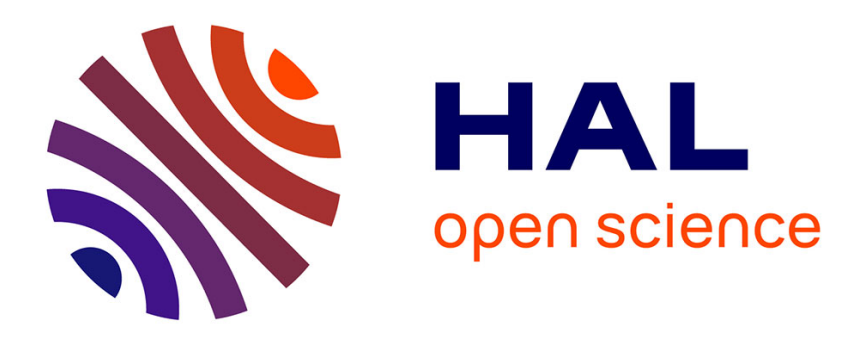

\title{
Localisation of Deformation and Damage under Adiabatic Compression
}

\author{
E. El-Magd, C. Treppmann, H. Weisshaupt
}

\section{To cite this version:}

E. El-Magd, C. Treppmann, H. Weisshaupt. Localisation of Deformation and Damage under Adiabatic Compression. Journal de Physique IV Proceedings, 1997, 07 (C3), pp.C3-511-C3-516. 10.1051/jp4:1997388 . jpa-00255545

\section{HAL Id: jpa-00255545 https://hal.science/jpa-00255545}

Submitted on 1 Jan 1997

HAL is a multi-disciplinary open access archive for the deposit and dissemination of scientific research documents, whether they are published or not. The documents may come from teaching and research institutions in France or abroad, or from public or private research centers.
L'archive ouverte pluridisciplinaire $\mathbf{H A L}$, est destinée au dépôt et à la diffusion de documents scientifiques de niveau recherche, publiés ou non, émanant des établissements d'enseignement et de recherche français ou étrangers, des laboratoires publics ou privés. 


\title{
Localisation of Deformation and Damage under Adiabatic Compression
}

\author{
E. El-Magd, C. Treppmann and H. Weisshaupt*
}

RWTH Aachen University of Technology, Department of Materials Science (LFW), Augustinerbach 4, 52056 Aachen, Germany

* Rheinmetall Industrie Aktiengesellschaft, Unterlüss, Germany

\begin{abstract}
For dynamic compressive tests, the conditions of friction between the contact surfaces of the specimens and the bars are found to cause mechanical instability of materials with low strain hardening and low strain rate sensitivity. The adiabatic flow curves are described by a model using a weakening parameter taken into account both damage and thermally induced instability. In this paper, a material model is used, which is able to describe the material behaviour in the whole range of deformation, i.e. in the region of thermally activated processes with gradual transition to the region of damping-controlled processes.
\end{abstract}

Résumé: Dans les essais de compression dynamique, les conditions de frottement des surfaces de contact entre l'échantillon et les barres sont à l'origine des instabilités mécaniques des matériaux possédant une faible sensibilité à la vitesse de déformation. Les courbes de contrainte d'écoulement adiabatiques sont définies par un modèle utilisant un facteur d'adoucissement qui tienne compte de l'endommagement et des instabilités thermiques. Dans cette publication on utilisera un modèle capable de décrire le comportement du matériau dans tout le domaine de déformation., $\mathrm{c}$. à $\mathrm{d}$. dans le domaine des mécanismes d'activation thermique avec passage progressif au domaine des mécanismes d'amortissement contrôlé.

\section{INTRODUCTION}

The mechanical behaviour of materials at high strain rates is characterised by an increased strain rate sensitivity, by the adiabatic character of the deformation process and by increasing effects of mass inertia forces leading to the propagation of mechanical waves and the reflections at the boundaries of the specimens. In addition, damage can occur at higher strains. The destabilizing effects were investigated on a variety of materials, such as Armco-iron and heat-treatable steels, using a Split-Hopkinson-Bar arrangement. The continuous transition between thermal activation and damping is described considering the free motion time from dislocations and the waiting time interval from dislocations in front of barriers. The transition range is of special interest in this investigation. An attempt is made to develop a model in order to describe the material behaviour for repeated loading and thus increasing damage. The localisation of the deformation and damage were investigated by metallographic examinations on the loaded specimens. The shape and degree of strain localisation are strongly dependent on the strain rate. A numerical analysis by Finite Elements for transient dynamic behaviour is used to study the effects of the. strain rate, the inertia forces, and the heat due to plastic work on the deformation process.

The test equipment used is a Split-Hopkinson-pressure bar with the possibility of cooling the specimen by liquid nitrogen. The test temperature range is between room temperature and $93 \mathrm{~K}$. The projectile acceleration unit consists of a compressed air tank, a quick-opening valve and an acceleration pipe, in which a projectile is accelerated up to $50 \mathrm{~m} / \mathrm{s}$. The maximum strain rate achieved is about $10^{4} \mathrm{~s}^{-1}$. Overviews concerning the mechanical behaviour under high strain rates are represented e.g. in [1-4].

\section{STRUCTURE MECHANICAL MODELS}

The macroscopic plastic strain rate results from the accumulation of the submicroscopic slip events caused by dislocation motion per time unit $\dot{\varepsilon}=b \cdot N_{m} \cdot v / M_{T}$, where the Burgers vector $b$ and the Taylor-factor $\mathrm{M}_{\mathrm{T}}$ are material constants, $\mathrm{N}_{\mathrm{m}}$ is the mobile dislocation density which is mainly a function of strain and $\mathrm{v}$ is the dislocation velocity which depends on the stress.

Different deformation mechanisms can be related to different strain rates and temperatures. Below a specific strain rate, which is dependent on temperature, only a slight influence of strain rate and 
temperature on the flow stress is observed. In this region (a) athermal deformation processes are dominant, in which the dislocation motion is influenced by internal long range stress fields, induced by such barriers as grain boundaries, precipitations and secondary phases. The athermal stress is represented by the sum of the contributions of the dislocations, precipitations, grain boundaries and secondary phases.

$$
\sigma_{\mathrm{a}}=\sigma_{\mathrm{dis}}+\sigma_{\mathrm{pr}}+\sigma_{\mathrm{gb}}+\sigma_{\mathrm{ph}}
$$

The flow stress follows approximately the same temperature function as the modulus of elasticity.

The thermal activated deformation (b) is characterised by short range stress fields induced by barriers like forest dislocations and solute atom groups in fcc.-materials or by periodic lattice potential (Peierls-stress) in bcc.-materials. If the stresses are high enough, a barrier can be overcome at once. At lower stresses a waiting time $\Delta \mathrm{t}_{\mathrm{w}}$ is required till thermal fluctuation can help in overcoming the barrier. The dislocation line becomes free to run a mean distance $\mathrm{s}^{*}$ until it stops after the motion time $\Delta \mathrm{t}_{\mathrm{m}}$ at the next barrier. The mean dislocation velocity is given by $v=s^{*} /\left(\Delta t_{w}+\Delta t_{m}\right)$ [6]. The waiting time equals the reciprocal value of the frequency $v_{0}$ of the overcoming attempts which follows an Arrhenius relation, so that

$$
\Delta t_{w}=\frac{1}{v_{0}} \exp \left(\frac{\Delta G}{k \cdot T}\right)
$$

The motion time is given by [7]:

$$
\Delta \mathrm{t}_{\mathrm{m}}=\frac{\mathrm{B} \cdot \mathrm{s}^{\cdot}}{\mathrm{b} \cdot\left(\sigma-\sigma_{\mathrm{a}}\right)} .
$$

If the strain rate is lower than some $10^{3} \mathrm{~s}^{-1}$, it can be assumed that $\Delta t_{\mathrm{w}}>\Delta \mathrm{t}_{\mathrm{m}}$. The activation energy depends on the difference $\sigma^{*}$ between the applied stress and the athermal stress according to $\Delta \mathrm{G}=\Delta \mathrm{G}_{0}-$ f $V^{*} d \sigma^{*}$, where $V^{*}=b \cdot l^{*} \cdot s^{*} / M_{T}$ is the reduced activation volume. Some experimental investigations showed a non-linear relation between $\sigma$ and $\Delta \mathrm{G}$ yielding a stress dependent activation volume. These nonlinearities were described by Vöhringer $[8,9]$ and Kocks [10] using:

$$
\dot{\varepsilon}=\dot{\varepsilon}_{0} \cdot\left[-\frac{\Delta \mathrm{G}_{0}}{\mathrm{k} \cdot \mathrm{T}}-\left(1-\ln \left(\frac{\left(\sigma-\sigma_{\mathrm{a}}\right)}{\left(\sigma_{0}-\sigma_{\mathrm{a}}\right)}\right)\right)^{\mathrm{p}}\right]^{\mathrm{q}} \text {. }
$$

At strain rates higher than some $10^{3} \mathrm{~s}^{-1}$, the stress is high enough, so that $\Delta \mathrm{t}_{\mathrm{w}}$ can be neglected compared to the motion time $\left(\Delta \mathrm{t}_{\mathrm{w}}<\Delta \mathrm{t}_{\mathrm{m}}\right)$. In this range of linear viscous behaviour damping effects dominate. The dislocation velocity yields to $v=s^{*} / \Delta t_{m}[7]$. The flow stress can be represented by

$$
\sigma=\sigma_{h}(\varepsilon)+\eta \cdot \dot{\varepsilon}
$$

where $\eta=M_{T} \cdot B /\left(b^{2} \cdot N_{m}\right)$ and $\sigma_{h}$ is the stress required to overcome barriers without thermal activation. It can be determined by extrapolation of the stress values to $\dot{\varepsilon}=0$.

In the range between the thermal activation and damping a continuous transition takes place. Both time intervals, the waiting time and the motion time have to be considered. When $s^{*}$ is the mean free distance, the dislocation velocity $v$ is given then by $v=s^{*} /\left(\Delta t_{m}+\Delta t_{w}\right)$, so that the strain rate can be determined considering eq.(4) introduced by Vöhringer and Kocks:

$$
\dot{\varepsilon}=\dot{\varepsilon}_{0}\left\{\exp \left[\frac{\Delta \mathrm{G}_{0}}{\mathrm{k} \cdot \mathrm{T}}\left(1-\left(\frac{\sigma-\sigma_{\mathrm{a}}}{\sigma_{0}-\sigma_{\mathrm{a}}}\right)^{\mathrm{p}}\right)^{\mathrm{q}}\right]+\frac{\eta \cdot \dot{\varepsilon}_{0}}{\sigma-\sigma_{\mathrm{a}}}\right\}^{-1}
$$

Figure 1 shows the thermal activated component of stress $\left(\sigma-\sigma_{a}\right)$ and the activation energy $\Delta \mathrm{G}$. Figure la shows the curve for the thermal activated behaviour and the curves for damping behaviour according to eq.(5) at different temperatures. The transition behaviour expressed by eq.(6) is shown in Figure lb with first experimental results. For a systematic determination of the parameters for each material, the number of experiments is still too small. So all investigated materials are shown (Armco-iron, 42 CrMo 4 and 25 CrMo 4 in tempered and hardened condition) demonstrating that the thermal activated component of stress depends mainly on the matrix of the material and not on the precipitation and the ageing condition. 


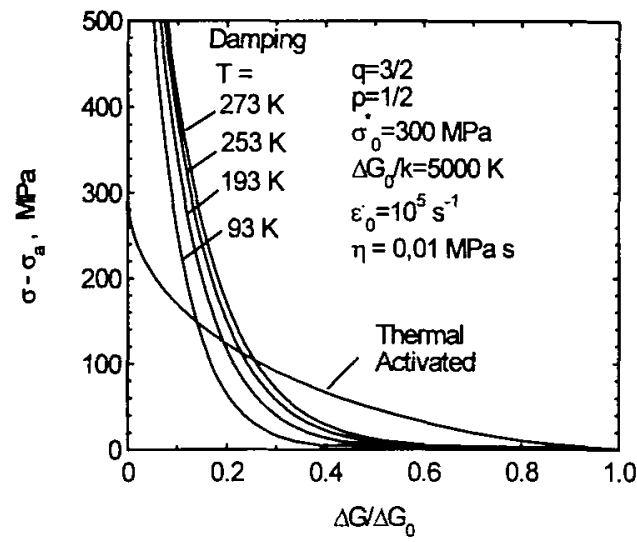

a)

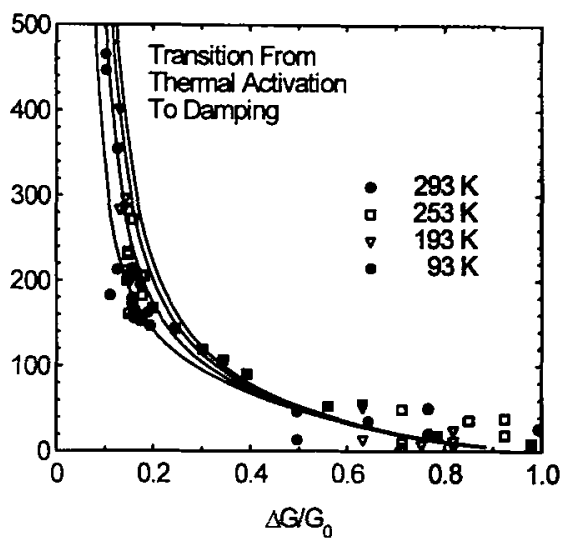

b)

Figure 1: a) Thermal activated and damping behaviour as a function of stress $\sigma-\sigma_{a}$ and activation emergy

b) Transition from thermal activation to damping according to eq.(6) for different materials

\section{LOCALISATION OF DEFORMATION AND DAMAGE}

Under dynamic loading, the deformation process can be considered to be adiabatic, as there is not enough time for heat transfer. Approximately $90 \%$ of the deformation work is transfered into heat:

$$
\rho \cdot c \cdot d T=\kappa \cdot \sigma_{\text {is }} \cdot d \varepsilon,
$$

where $\rho$ is the density of the material, $\mathrm{c}$ the specific heat capacity. The remaining $10 \%$ of the deformation energy is consumed by the lattice in increasing the internal energy due to dislocation multiplication, etc. According to eq.(5) and taking into consideration that the flow stress decreases exponentially with increasing temperature, the isothermal stress can be written as:

$$
\sigma_{\text {is }}=\left(K \cdot \varepsilon^{n}+\eta \cdot \dot{\varepsilon}\right) \cdot \exp \left(-\beta \cdot \frac{T-T_{0}}{T_{M}}\right),
$$

$T$ is the material temperature, $T_{0}$ is a reference temperature and $T_{M}$ the melting temperature. $\boldsymbol{\beta}$ denotes a material constant having values about 3 [3]. With eq.(7) and (8) the adiabatic stress can be written as

$$
\sigma_{\mathrm{ad}}=\frac{K \cdot \varepsilon^{\mathrm{n}}+\eta \cdot \dot{\varepsilon}}{1+\frac{\kappa \cdot \beta}{\rho \cdot c \cdot T_{M}}\left(\frac{K}{n+1} \varepsilon^{n+1}+\eta \cdot \varepsilon \cdot \dot{\varepsilon}\right)},
$$

which is a further developed form of the formulations given in [11] und [12]. Due to the balance between strain hardening and thermal stress reduction, this curve shows a maximum $\sigma_{0}$ at a critical strain. The determination of the parameters is shown i.e. in [13].

In experiments, Materials with low strain hardening and low strain rate sensitivity show a higher decrease of strain than it can be explained by adiabatic character of the deformation process [14]. It is assumed, that the stress decreases due to additional thermal localisation and structural damage. This additional effects can be discribed by a damage function $f(D)=\exp (-D)$ :

$$
\sigma_{\text {is }}=\left(K \cdot \varepsilon^{n}+\eta \cdot \dot{\varepsilon}\right) \cdot \exp \left(-\beta \cdot \frac{T-T_{0}}{T_{M}}\right) \cdot \exp (-D) \text {. }
$$

With $\Omega=\beta \cdot \frac{T-T_{0}}{T_{M}}+D$ both exponential functions can be described together. The assumption that the damage increment $\mathrm{dD}$ is proportional to the work increment done on the material per unit volume yields to:

$$
\mathrm{dD}=\mathrm{P}_{\mathrm{D}}^{*} \cdot \sigma \cdot \mathrm{d} \varepsilon .
$$

The proportional factor $\mathrm{P}_{\mathrm{D}}{ }^{*}$ describes the structural damage. The localisation of temperature yields with eq.(7) to 


$$
\mathrm{dT}=\left(\frac{\kappa}{\rho \cdot \mathrm{c}}+\mathrm{P}_{\mathrm{T}}^{*}\right) \cdot \sigma_{\mathrm{is}} \cdot \mathrm{d} \varepsilon,
$$

Values for $\mathrm{P}_{\mathrm{T}}{ }^{*}$ greater then zero represent a thermal localisation in the specimen.

The increment $d \Omega$ is then given by:

$$
\mathrm{d} \Omega=\frac{\beta}{T_{M}} \mathrm{~d} T+\mathrm{dD}=\left(\frac{\kappa \cdot \beta}{\rho \cdot c \cdot T_{M}}+\frac{\beta}{T_{M}} P_{T}^{*}+P_{D}^{*}\right) \cdot \sigma \cdot d \varepsilon,
$$

which yields to the reduced adiabatic stress:

$$
\sigma_{\mathrm{ad}, \mathrm{r}}=\frac{\mathrm{K} \cdot \varepsilon^{\mathrm{n}}+\eta \cdot \dot{\varepsilon}}{1+\left(\kappa+\mathrm{P}_{\mathrm{T}}+\mathrm{P}_{\mathrm{D}}\right) \frac{\beta}{\rho \cdot c \cdot \mathrm{T}_{M}}\left(\frac{\mathrm{K}}{\mathrm{n}+1} \varepsilon^{\mathrm{n}+1}+\eta \cdot \varepsilon \cdot \dot{\varepsilon}\right)},
$$

where

$$
\mathrm{P}_{\mathrm{T}}=\rho \cdot c \cdot \mathrm{P}_{\mathrm{T}}^{*} \text { and } \mathrm{P}_{\mathrm{D}}=\frac{\rho \cdot c \cdot \mathrm{T}_{\mathrm{M}}}{\beta} \cdot \mathrm{P}_{\mathrm{D}}^{*}
$$

$P_{D}=P_{T}=0$ means a pure adiabatic behaviour, if $\left(P_{D}+P_{T}\right)>0$ the stress is reduced by mat iocalisation and/or by structural damage. Figure 3 shows the extrapolated stress $\sigma_{0}=\left(\sum \sigma_{-1}, \cdots\right.$, i and the true strain for $25 \mathrm{CrMo} 4$ in two different heat treatments and for Armco-Iron.

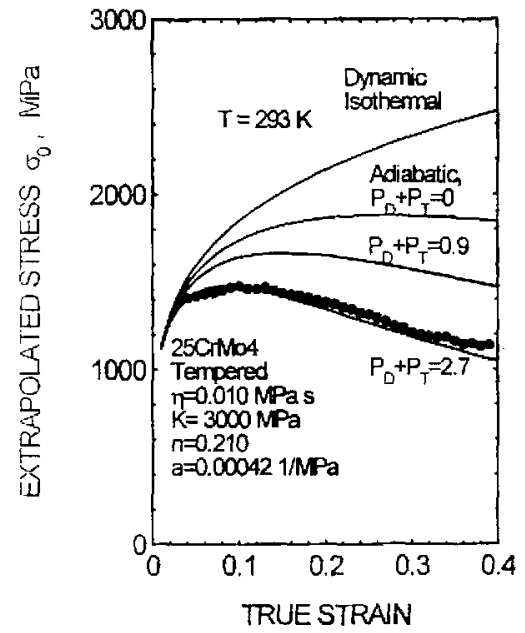

a)

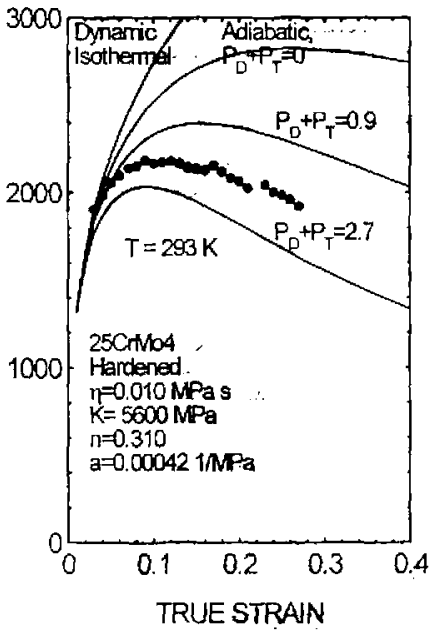

b)

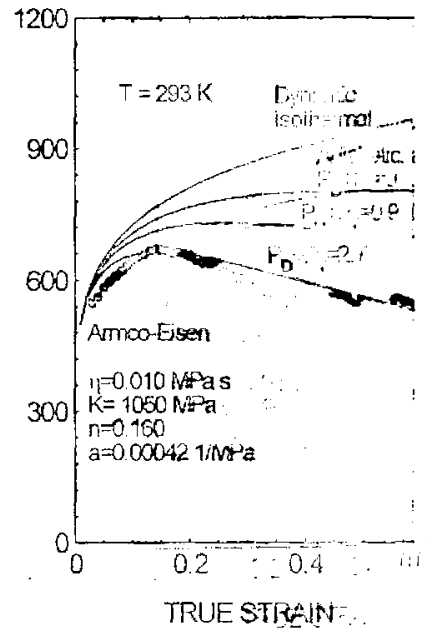

c)

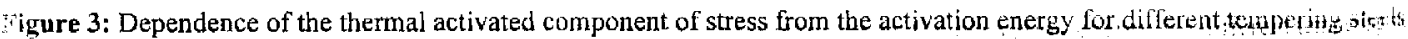
and Armco-iron

Only with the value of $\left(\mathrm{P}_{\mathrm{D}}+\mathrm{P}_{\mathrm{T}}\right)$, it is not possible to decide how much of the stress reduction belongs to the thermal localisation and how much to structural damage. For this decision, additional iests have to be done. If a specimen is cooled down to room temperature after an experiment, all thermal stress reductions muln. effects will become zero. A repeated loading of the specimen leads to one point of the calculated isothermal curye $\left(\sigma_{\text {iso }}\right)$, if 11111 ructural damage and can be neglected. Otherwise a stress value

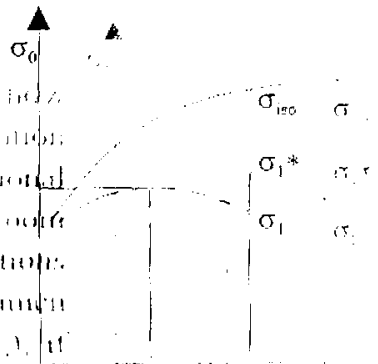
$\sigma_{i}^{*}$ ) between $\left(\sigma_{1}\right)$ and $\left(\sigma_{i s o}\right)$ will be reached.

n order to calculate the reduced adiabatic flow curve for Figure 2: Schemalic vien of repcated tuilting. cepated loading, the integration of eq.21 has to be done from any strain value $\varepsilon_{j-1}$ to $\varepsilon_{\mathrm{j}}$ and $\Omega$ from $\Omega_{\mathrm{j}-1}$ to $\Omega_{\mathrm{j}}$ : 
whibhyidets to;

$$
\int_{\Omega_{j=1}}^{Q_{j}} \exp (\Omega) d Q \Omega=\frac{\beta}{\beta \cdot c \cdot \overline{T_{M}}}\left(k+\theta_{T} \neq \theta_{\mathrm{B}}\right) \int_{\varepsilon_{j=1}}^{\varepsilon_{j}} \sigma \cdot d \mathrm{~d},
$$

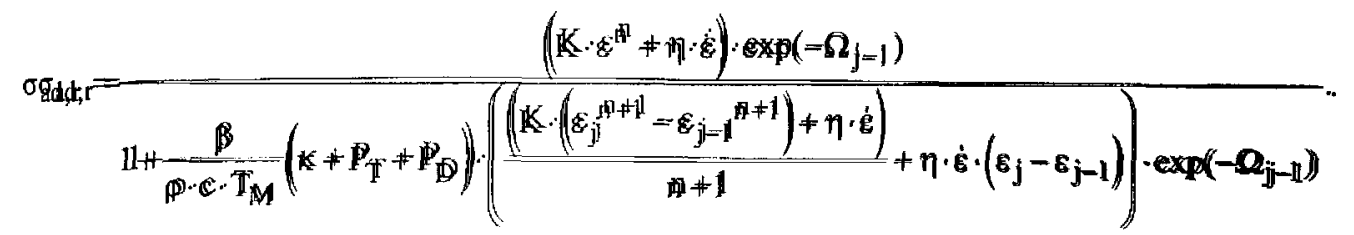

Fonthefinsti inquat (j=1) $\Omega_{0}$ atd $\varepsilon_{0}$ is ststrssoq, iss given by:

$$
\sigma_{11}=\frac{\sigma_{\text {iso }}}{\left.1+\frac{\beta}{P \cdot c \cdot T_{M}}\left(K+P_{T}+\mathbb{P}_{\mathbb{D}}\right)\right) \cdot\left(\frac{\left(K_{1}{ }^{n+1}+\eta \cdot \dot{\varepsilon}\right)}{n+1}+\eta \cdot \dot{\varepsilon} \cdot \varepsilon_{1}\right)}
$$

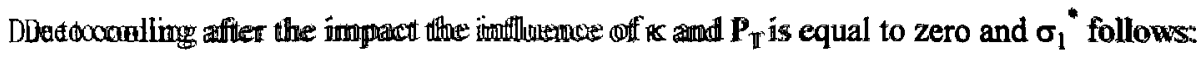

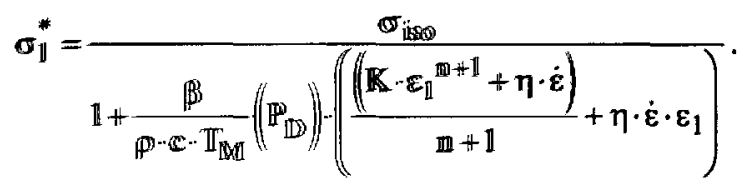

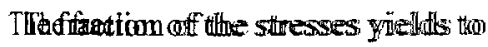

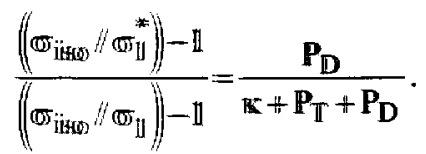

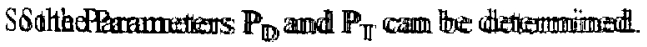

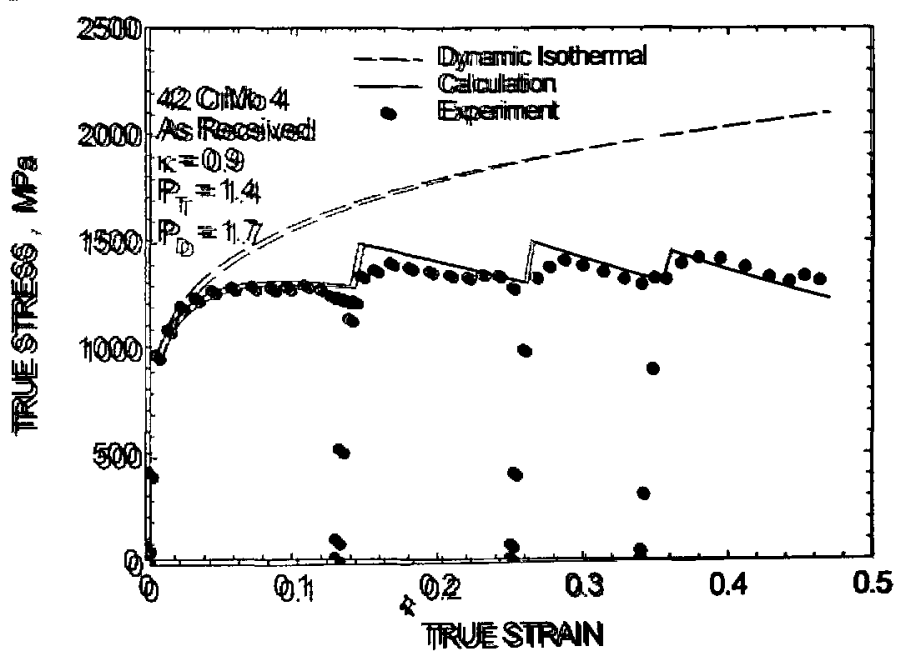

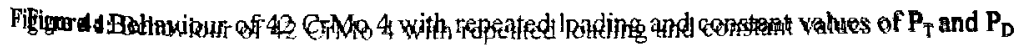




\section{RESULTS FROM METALLOGRAPHICAL INVESTIGATIONS AND FE-CALCULATION}

The polished and etched cross sections of the specimens show high distorted flow lines as a result of friction between the specimen ends and the loading tool. The cross section of quasistatic deformed specimens show triangular regions of restricted deformation at both ends of the specimens. Figure 5 show a specific characteristic appearance of impact specimen of Armco-iron. After etching, the more deformed regions of the specimens are darker than the less deformed. There is only one compression cone on the reflection side of the specimen. This specific characteristic appearance is the result of wave propagation and reflection effects due to mass inertia forces.

The Finite Element method was used to determine the formation of the internal compression cones. The two-dimensional finite element code was developed for analyses of transient dynamic behaviour with explicit integration. The mass inertia forces are taken into consideration by regarding the material mass to be lumped at the nodes. At both contact surfaces Coulomb friction $\tau=\mu \cdot \sigma$ is assumed $(\mu=0.1)$.

An example for the simulation results is shown in Figure 6 for Armco-iron whose flow stress is described by eq (5).

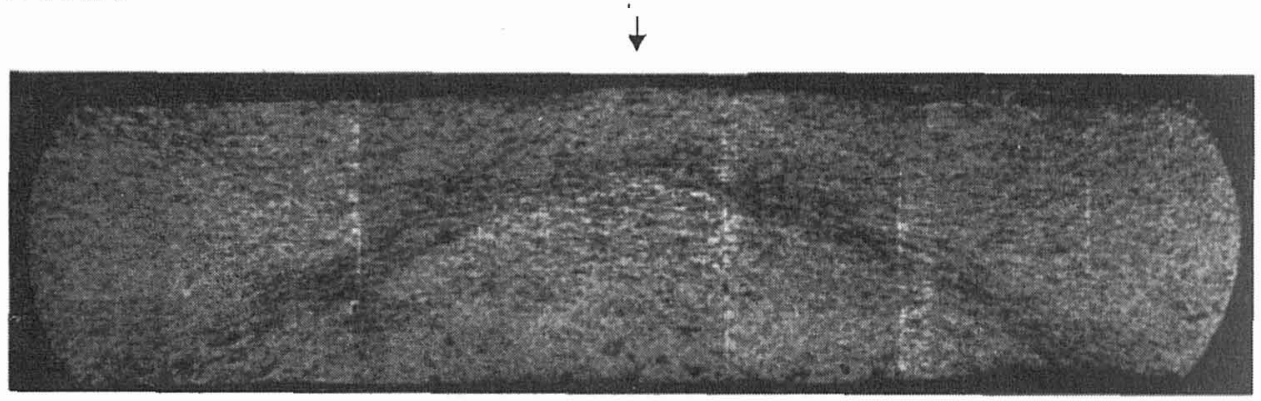

Figure 5: cross-section of an etched and polished specimen

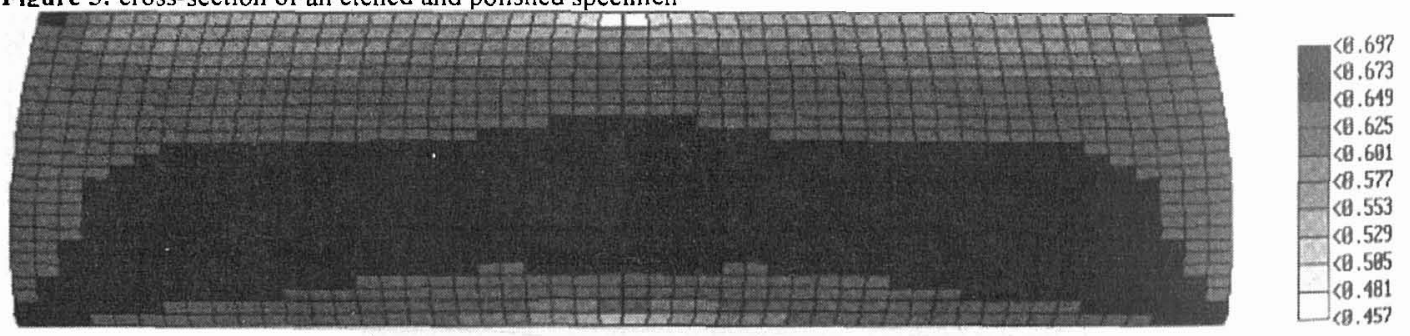

Figure 6: Equivalent plastic strain

\section{References}

[1] Campbell, J.D., Springer Verlag, Wien, NY, 1972

[2] Harding, J.: in Chiem, C.Y.;Kunze, H.D. and Meyer, L.W. (ed.), DGM, Oberursel, Germany, 1988

[3] El-Magd, E., Journal de Physique IV, C8 Vol. 4,pp. 149 - 170

[4] El-Magd, E., Proc. Workshop, Neustadt a. Rbge: 6. bis 9. Juli 1992

[5] Campbell, J.D. and Ferguson, W.G.: Phil.Mag., Vol. 21, 1970, pp. 63-82

[6] Kumar, A. and Kumble, R.G.J. Appl. Phys.,40, 3475-3480 (1969)

[7] Kumar, A., Hauser, F.E. and Dorn, J.E.: Acta met. 16(1968), pp. 1189-1197

[8] Vöhringer, O.: Habilitationsschrift, TH Karlsruhe, 1972

[9] Macherauch, E. and Vöhringer, O.: Z. Werkstofftechnik 9(1978) pp. 370-391

[10] Kocks, U.F., Argon, A.S. and Ashby, M.F. Pergamon Press, NY 1975

[11] Troost, A. and El-Schennawi, A., Mech. Res. Comm. 1(1974), pp 331-334

[12] Dormeval, R., in Blazyniski, Elsevier appl.. Sc., London 1988, pp 47-70

[13]El-Magd, E., Scholles, H. and Weisshaupt, H., Mat.wiss. u. Werkstofftechnik,Vol.2(1996) pp408-41\}

[14] Ichwan, M., Dr.-Ing. Dissertation, RWTH-Aachen 1992 